Ensino, Saúde e Ambiente-V5 (2), pp. 234-245, ago. 2012

\title{
OS SENTIDOS DE “CONFLITO AMBIENTAL” NA EDUCAÇÃO AMBIENTAL: UMA ANÁLISE DOS PERIÓDICOS DE EDUÇÇÃ̃O AMBIENTAL
}

\section{THE MEANINGS OF "ENVIRONMENTAL CONFLICT" IN ENVIRONMENTAL EDUCATION: AN ANALYSIS OF JOURNALS ON ENVIRONMENTAL EDUCATION}

\author{
Angélica Cosenza', Isabel Martins ${ }^{2}$ \\ ${ }^{1}$ Prof ${ }^{a}$. UFJF, doutoranda no Programa de Pós Graduação em Educação em Ciências e Saúde do Núcleo \\ de Tecnologia Educacional para a Saúde (NUTES) da UFRJ, bolsista CNPQ. \\ ${ }^{2}$ Prof a . do Programa de Pós Graduação em Educação em Ciências e Saúde do NUTES/UFRJ
}

\section{RESUMO}

Neste estudo, apresentamos um levantamento quantitativo, seguido de uma discussão qualitativa acerca dos diferentes sentidos associados à temática "conflitos ambientais" contidos nas publicações selecionadas de periódicos de pesquisas nacionais, e internacionais do campo da educação ambiental, até o ano de 2011. Nosso objetivo foi o de compreender os sentidos empregados aos conflitos ambientais na produção científica sobre educação ambiental e refletir sobre as contribuições que esta abordagem lança ou pode lançar - ao campo da educação ambiental. Utilizamos neste estudo, referenciais metodológicos decorrentes dos pressupostos da revisão narrativa e etnográfica de dados. Os resultados apontam para uma produção ainda incipiente da interface pesquisada nos periódicos analisados. Contudo, referências à justiça e conflito ambientais no âmbito da EA vêm sendo mobilizadas no sentido de rever concepções e práticas tradicionais de EA postas a serviço da alienação e desigualdade socioambiental.

Palavras-chave: conflito ambiental, educação ambiental, revisão narrativa

\begin{abstract}
In this paper, we present a quantitative survey, followed by a qualitative discussion about the different meanings associated to the "environmental conflicts" theme contained in selected publications of national and international research journals on the field of environmental education until 2011. Our aim was to comprehend the meanings employed to the environmental conflicts in the scientific production about environmental education and to reflect on the contributions cast by this approach - or that it may cast - on the field of environmental education. In this study, we use methodological references originated from presuppositions of narrative and ethnographic review of data. The results indicate a still incipient production of the interface researched in the journals analyzed. However, references to trials and environmental conflicts within the scope of EE are being mobilized in order to review traditional practices and conceptions of EE put at service of alienation and socioenvironmental inequality.
\end{abstract}

Key words: environmental conflict, environmental education, narrative review 


\section{Introdução}

Neste estudo, apresentamos um levantamento quantitativo, seguido de uma discussão qualitativa acerca dos diferentes sentidos associados a "conflito ambiental" contidos nas publicações selecionadas de periódicos nacionais e internacionais de pesquisa do campo da educação ambiental, até o ano de 2011. Partimos de um levantamento mais geral para identificar artigos que faziam referência no título, no resumo e/ou em suas palavras-chave aos termos "conflito ambiental", "justiça ambiental" para então realizar uma leitura sistemática de um conjunto particular de artigos filtrados com o objetivo de descrever e discutir possíveis interfaces entre a temática dos conflitos ambientais e a educação ambiental (EA). A escolha dos termos conflito ambiental e justiça ambiental, justifica-se por seu entrelaçamento histórico, teórico e epistemológico (ACSELRAD, MELLO, BEZERRA, 2009).

$\mathrm{O}$ estudo foi motivado pela tentativa de 1) compreender qualitativamente quais os sentidos da temática "conflito ambiental" na produção científica sobre EA, ou seja, com quais sentidos essa temática vem sendo usada na literatura da EA e, 2) refletir sobre as contribuições que ela lança - ou pode lançar - ao campo da educação ambiental e vice-versa.

Esse estudo justifica-se pela oportunidade de ampliar o diálogo entre a educação ambiental e o campo dos conflitos ambientais. Surge assim, a partir de algumas inquietações: A articulação entre educação ambiental e conflitos ambientais é hoje uma preocupação teórica, epistemológica, pedagógica do campo da EA? Qual o papel da educação ambiental nas lutas políticas por justiça ambiental? Seriam os conflitos ambientais, ferramentas importantes na construção de educabilidade?

\section{A emergência do Movimento por Justiça Ambiental e dos Conflitos Ambientais}

Apesar de haver um consenso sobre a emergência e a seriedade da crise ambiental contemporânea, há diferentes representações político-ideológicas, por detrás de discursos por vezes conflitantes, que moldam a forma como indivíduos e grupos sociais passam a compreender os problemas socioambientais e a reagir a eles. A produção destes discursos no campo ambiental se faz visível quando analisamos respostas, posicionamentos ou possíveis explicações de diferentes setores sociais às indagações sobre causas, conseqüências e alternativas à crise socioambiental contemporânea. 
Alier (2007) considera o campo ambiental como plural, sujeito a uma multiplicidade de concepções/ações, e busca distingui-lo internamente a partir de três correntes: o culto ao silvestre, o evangelho da ecoeficiência e o ecologismo dos pobres ou justiça ambiental. A primeira corrente tem seu discurso identificado com práticas conservacionistas, na defesa de uma natureza intocada, na preservação da biodiversidade e demais recursos naturais. A segunda corrente, aposta no desenvolvimento sustentável, na modernização ecológica, na utilização racional de recursos, defendendo o modelo de desenvolvimento sustentável dentro da ótica do sistema de valores capitalistas vigente.

Para Loureiro, Barbosa e Zborowski (2009), as duas primeiras correntes ao adotarem uma perspectiva puramente ecológica da crise e dos problemas ambientais, são legitimadas pela ideologia dominante, funcionam segundo a lógica do mercado ou sem questioná-la, não se preocupando com práticas transformadoras da ordem econômica vigente.

Estas correntes são hoje desafiadas, segundo Alier, por uma terceira chamada ecologismo dos pobres ou justiça ambiental que reconhece que impactos derivados do crescimento econômico não são solucionados somente por políticas econômicas ou por inovações tecnológicas e atingem desproporcionalmente alguns grupos sociais que protestam e resistem. O eixo discursivo principal dessa corrente não é uma reverência sagrada à natureza, mas antes, uma representação de ambiente a partir de conflitos ecológicos distributivos. Sua ética nasce de demanda contemporânea por justiça social entre humanos.

O movimento de Justiça ambiental nasce nos EUA nos anos 1980, a partir de uma articulação entre movimentos de caráter social, territorial, ambiental e de direitos civis. Reafirma-se no âmbito de lutas que procuraram expor que áreas de maior privação socioeconômica e/ou habitadas por grupos sociais e étnicos sem acesso às esferas decisórias do estado e do mercado, concentram a falta de investimento em infraestrutura de saneamento, a ausência de políticas de controle dos depósitos de lixo tóxico, a moradia de risco, entre outros fatores que forjam más condições ambientais de vida e de trabalho (ACSELRAD, MELLO, BEZERRA, 2009).

Para designar esse fenômeno de imposição desproporcional de riscos ambientais às populações menos dotadas de recursos financeiros e políticos, o movimento consagrou o termo injustiça ambiental. Como contraponto, está a reivindicação por justiça ambiental, compreendida como o tratamento justo e o envolvimento pleno dos 
grupos sociais, nas decisões sobre o acesso, a ocupação e o uso dos recursos ambientais em seus territórios. No âmbito do movimento ambientalista, essa noção tem sustentado discursos que se desdobram em reflexões e ações por integrar as lutas ambientais às sociais (ACSELRAD, MELLO, BEZERRA, 2009).

Mais do que uma expressão do campo do direito, justiça ambiental assume-se como campo de reflexão, mobilização e bandeira de luta de diversos sujeitos e entidades ${ }^{1}$. Como premissa fundamental dessa corrente no Brasil figura a defesa de que o processo de acumulação capitalista priva certos grupos sociais ao acesso aos recursos naturais e aos serviços ambientais e de qualidade de vida. Nesse processo, as mudanças nos modelos de desenvolvimento de determinadas localidades assumem maior impacto em grupos sociais mais expostos aos riscos, afetando a sua sobrevivência. Isso cria e reforça uma situação de expropriação e subordinação desses grupos submetidos à ótica do capital, sustentada por relações de poder assimétricas entre aqueles que detêm os meios de produção e outros a quem só restam os riscos (LOUREIRO, BARBOSA, ZBOROWSKI, 2009).

Partindo dessas premissas, é que Layrargues (2009) argumenta que a desigualdade não se manifesta apenas em termos econômicos de distribuição de renda: existe também uma dimensão ambiental na desigualdade, sendo o conflito socioambiental sua expressão nítida. Os conflitos ambientais polarizam sujeitos sociais em condições assimétricas de acesso ao poder. Nesta perspectiva os conflitos ambientais são:

\begin{abstract}
aqueles envolvendo grupos sociais com modos diferentes de apropriação, uso e significado do território, tendo origem quando pelo menos um dos grupos tem a continuidade das formas sociais de apropriação do meio que desenvolvem ameaçada por impactos indesejáveis-transmitidos pelo solo, água, ar ou sistemas vivos-decorrentes do exercício de práticas de grupos (ACSELRAD, 2004, p. 26).
\end{abstract}

A falta de políticas adequadas aos povos indígenas, a alteração do regime tradicional de uso e ocupação de terras por caiçaras, ribeirinhos, índios, pescadores artesanais e agricultores familiares, a construção de barragens, as indenizações irrisórias, a biodiversidade perdida, as comunidades afetadas, os direitos humanos violados, enfim, são temáticas que representam barbáries e que se desdobram em alguns dos conflitos ambientais no Brasil (FIOCRUZ, FASE, 2010).

\footnotetext{
${ }^{1}$ Manifesto de Lançamento da Rede Brasileira de Justiça Ambiental, criada em 2001, com o objetivo de combater as injustiças ambientais.
} 
Os conflitos, para além dos problemas ambientais, envolvem, via de regra, posições antagônicas de diferentes atores representadas em torno da utilização e/ou gestão do ambiente. Zhouri e Laschefski (2010) consideram haver três tipos de conflitos ambientais que podem ocorrer isoladamente ou coexistir: distributivos, espaciais e territoriais. Os distributivos são aqueles que, manifestadamente, indicam graves desigualdades sociais em torno do acesso e da utilização dos recursos naturais, tais como petróleo, água, florestas, pré-sal, etc.

Os conflitos espaciais abrangem aqueles causados por efeitos ou impactos que ultrapassam os limites entre os territórios de diversos agentes ou grupos sociais, tais como emissões gasosas, poluição da água, etc. Já os territoriais marcam situações em que existe sobreposição de reivindicações de diversos segmentos sociais, portadores de identidades e lógicas culturais diferenciadas, sobre o mesmo recorte espacial, como por exemplo, área de implementação de uma hidrelétrica versus territorialidade da população afetada.

A perspectiva conflitiva dos problemas ambientais é entendida assim, como manifestação de conflitos sociais entre interesses privados e públicos. Essa perspectiva implica, em práticas sociais de empoderamento e tomada de decisões, de que a educação é um exemplo, considerar contextos socioeconômicos, políticos e culturais em suas especificidades, reconhecer atores sociais em situação de risco e conflito socioambiental, compreender e desvelar assimetrias de poder e esquemas de opressão social que perpetuam desigualdades socioambientais (LAYRARGUES, 2009).

Em suma, considerar conflitos ambientais em um processo de luta por justiça ambiental, implica expor as contradições das sociedades assimétricas e desiguais e, por meio delas, operar em um processo consciente e dialógico de transformação e emancipação sociais.

\section{Metodologia do Estudo}

A pesquisa foi iniciada pela seleção de periódicos avaliados pelo sistema Qualis na área da educação: buscamos periódicos nacionais e internacionais do campo da educação associados à temática ambiental e que estivessem disponíveis online.

Analisamos todos os números publicados até o ano de 2011 dos seguintes periódicos: Ambiente e Educação: Revista de Educação Ambiental, Educação Ambiental em Ação, Ensino, Saúde e Ambiente, Revista Eletrônica do Mestrado em Educação Ambiental, Revista Pesquisa em Educação Ambiental, Revista Brasileira de 
Educação Ambiental, Revista Ambientalmente Sustentable, Canadian Journal of Environmental Education.

Num primeiro momento, foram identificados os artigos publicados nessas revistas que tratavam dos temas "conflito ambiental, "justiça ambiental", por meio da identificação dessas expressões nos campos título e/ou resumo e palavras-chaves. Desta forma, foram incluídos apenas textos nos quais as perspectivas "conflito ambiental", "justiça ambiental" tinham centralidade na discussão. Em seguida, procedemos a uma leitura sistemática de seus textos completos para compreender que temáticas ou categorias de discussão foram favorecidas nestes artigos e de que modo permitiam aproximações ou distanciamentos com a educação ambiental.

Utilizamos neste estudo, pressupostos da revisão narrativa e etnográfica de dados. Em tal abordagem, a análise dos textos se dá de forma flexível, demandando um tratamento descritivo dos dados, construídos no processo de leitura e entrecruzamento de textos selecionados e considerados relevantes. Aqui não há intenção de uma revisão para "esgotar o assunto", nem produzir generalizações ou estabelecer perguntas do tipo causa e efeito. O levantamento, assim se deu em um movimento interpretativo, mais voltado à geração de entendimento do que acumulação de informações sobre o campo da EA em interface com o debate dos conflitos ambientais (BRYMAN, 2004).

Nosso trabalho consistiu em selecionarmos os textos de interesse, procedermos a uma leitura exaustiva dos mesmos, buscando complementaridades, refutações, confirmações, entre trechos específicos dentro dos textos selecionados, trechos estes que tratavam de definições dos objetos de estudo, dos pressupostos, das formulações teóricas dos estudos descritos nesses textos e produzir um mapeamento interpretativo para nossas questões de interesse (BRYMAN, 2004). Assim, esse estudo foi marcado por um movimento interpretativo, interessado em produzir uma elaboração teórica sobre o modo particular como os artigos filtrados denotavam sentidos para a questão dos conflitos ambientais.

A tabela 1 descreve, nos oito periódicos analisados, a distribuição dos artigos vinculados às temáticas pesquisadas. É possível observar uma pequena expressividade de publicações nessa linha. Entretanto, reconhecemos os limites dessa afirmação, levando em conta o caráter multidisciplinar da EA e a ocorrência de significativas publicações de educação ambiental em periódicos de diversas áreas, entre elas educação, ecologia, ensino de ciências, ciências sociais, geografia, ciências agrárias, dentre outras. 
É interessante ver como, apesar do debate sobre justiça e conflitos ambientais ter sua origem em movimentos norte-americanos desde a década de 80 (ACSELRAD, MELLO, BEZERRA; 2009), a julgar pela ausência de referências específicas nos títulos/resumos/palavras-chave, os periódicos internacionais de EA estudados parecem não refletir essa articulação com centralidade. No entanto, reconhecemos ser importante, levantar a produção científica do periódico Environmental Education Research, pela sua relevância acadêmica e prestígio junto aos pesquisadores do campo.

Tabela 1: Distribuição de artigos que apresentam a temática “conflitos ambientais" em periódicos do campo da educação ambiental

\begin{tabular}{|c|c|c|c|}
\hline Periódico & $\begin{array}{c}\text { Total de } \\
\text { artigos } \\
\text { publicados }\end{array}$ & $\begin{array}{c}\text { Total de } \\
\text { artigos que } \\
\text { mencionam } \\
\text { 'conflito } \\
\text { ambiental' }\end{array}$ & $\begin{array}{c}\text { Período } \\
\text { analisado }\end{array}$ \\
\hline Ambiente e Educação & 176 & 1 & 1996 a 2011 \\
\hline Educação Ambiental em Ação & 246 & 0 & 2002 a 2011 \\
\hline Ensino, Saúde e Ambiente & 82 & 0 & 2008 a 2011 \\
\hline Revista Eletrônica do Mestrado em & 401 & 4 & 2004 a 2011 \\
\hline Educação Ambiental & & 0 & 2006 a 2011 \\
\hline Revista Pesquisa em Educação Ambiental & 102 & 0 & 2010 a 2011 \\
\hline Revista Brasileira de Educação Ambiental & 23 & 0 & - \\
\hline Revista Ambientalmente Sustentable & 93 & 0 & 1996 a 2011 \\
\hline Canadian Journal of Environmental & 225 & 1348 & 010 \\
\hline
\end{tabular}

Também é importante dizer que nos periódicos brasileiros de EA a preocupação com a questão dos conflitos e justiça ambientais vem intensificando-se na agenda da produção da EA apenas nos últimos anos, período em que também se dá a emergência do movimento de Justiça Ambiental no Brasil, bem como uma maior publicização dos conflitos ambientais.

A análise foi iniciada a partir da leitura dos resumos, com a classificação dos artigos em três categorias, que dizem respeito a aspectos do formato e do gênero dos 
textos. São eles: Relato de Pesquisa Empírica; Ensaio; Revisão de Área. Os dados encontrados são expostos na tabela 2.

Os artigos categorizados como Ensaios, foram aqueles que apresentavam uma reflexão acerca da articulação pesquisada, fundamentada em bibliografia, incluindo comentário ou posicionamento do autor. Constatamos uma alta freqüência da categoria ensaio. Estes artigos, todos brasileiros por sua vez, assumiram questões em sua maioria voltadas a formulação de pressupostos teóricos, pedagógicos, históricos, epistemológicos para fundamentar a articulação desejada entre as áreas.

Percebemos nesse conjunto de quatro ensaios, certa variedade de questões e objetos de pesquisas, típicas da variedade de preocupações históricas que marcam o campo da educação ambiental no Brasil. Essas questões posicionam a relação EA/conflito ambiental e/ou EA/justiça ambiental em torno de quatro temáticas distintas: na formulação teórica entre sustentabilidade e educação para cidadania (CARVALHO, 2008), no tratamento pedagógico da temática "resíduos sólidos" (GUANABARA, GAMA, EIGENHEER, 2008), na construção de premissas teóricas para uma educação ambiental transformadora ancoradas no pensamento crítico (LOUREIRO, 2003), na defesa da justiça ambiental na formação de bacharéis de direito (FILHO, 2011).

Tabela 2: Gênero do artigos que apresentam a temática "conflitos ambientais" em periódicos do campo da educação ambiental

\begin{tabular}{|c|c|c|}
\hline Tipos de artigos & $\begin{array}{c}\text { Total de artigos } \\
\text { encontrados }\end{array}$ & $\%$ \\
\hline Relatos de pesquisa empírica & 2 & $33,3 \%$ \\
\hline Ensaio & 4 & $66,7 \%$ \\
\hline Revisão de área & 0 & 0 \\
\hline Total & 6 & $100 \%$ \\
\hline
\end{tabular}

Cassificamos como relatos de pesquisa empírica aqueles que continham fundamentação teórico-metodológica vinculada às temáticas investigadas, descrição de procedimentos de obtenção e análise de dados empíricos e discussão de resultados. Assim, dois artigos foram categorizados como relatos de pesquisa empírica. Um deles trata sobre a aprendizagem da ética construída em um curso sobre justiça ambiental da Universidade de Vermont, Estados Unidos (KAZA, 2002). Outro (JABER \& SATO, 2010), explora conflitos ambientais que se estabelecem nos territórios mato-grossenses e parte de seu reconhecimento para desvelar determinadas práticas de exclusão e injustiças ambientais. Entretanto, a baixa freqüência de relatos de pesquisa empírica parece refletir a incipiência das temáticas investigadas no âmbito da EA. 
Partimos da premissa de que revisões de área são artigos que apresentam levantamentos da produção científica de um campo ou de uma temática de interesse. Artigos de revisão de área contribuem para melhor conhecer e organizar a produção científica de um campo. A inexistência desse tipo de trabalho na interface pesquisada, torna mais difícil conhecer a produção fronteiriça entre educação ambiental e conflitos ambientais e compreender as possibilidades e os limites de trabalhos que se propõe a estabelecer essa interação.

\section{Os sentidos de Justiça e Conflito Ambiental na Educação Ambiental}

$\mathrm{Na}$ leitura sistemática dos seis artigos selecionados, percebemos que as referências à justiça e conflito ambientais no âmbito de suas contribuições à EA operam a partir de alguns deslocamentos, a saber: 1) a defesa de uma educação vinculada a um projeto de sustentabilidade político de redistribuição equitativa de bens em termos globais e locais, 2) a defesa de que os conflitos operam a favor de um maior reconhecimento dos atores sociais em situação de risco, para além de mapeamento de problemas ambientais, 3) a defesa de uma educação política, ética e moral no âmbito de processos educativos que se pretendam emancipatórios em contraposição á uma prática educativa desvinculada do compromisso social.

A contribuição da educação ambiental na edificação de uma sociedade sustentável, remete ao debate contemporâneo sobre a Educação Ambiental, que ganhou maior expressão a partir do Fórum das ONGs na RIO-92 e encontra ressonância no âmbito da Política Nacional de Educação Ambiental (PNEA).

A noção de sustentabilidade tem sido usada indiscriminadamente produzindo a falsa idéia de que há um consenso sob todos os discursos que acionam este conceito. Inversamente, os artigos pesquisados parecem partilhar da crítica à idéia de sustentabilidade caracterizada no âmbito de um cenário desenvolvimentista, pensada sob a ótica do mercado. Assim, os artigos pesquisados operam um primeiro deslocamento importante às práticas de EA: ressaltam que a sustentabilidade não é neutra, nem tampouco homogênea, pois pode ser apropriada por forças hegemônicas na perpetuação de seus mecanismos de dominação e por forças emancipatórias e populares na construção de uma nova racionalidade produtiva.

Semelhante consideração está bem expressa em Carvalho (2008) que busca contrapor conflitantes paradigmas de sustentabilidade. A noção de conflito surge, em suas idéias, associada à preocupação com a injustiça ambiental. Nesta perspectiva, para 
a autora, o processo de construção de sustentabilidade não se dá pela tentativa de "resolver" conflitos num amplo consenso em torno de interesses comuns. Trata-se de construir a sustentabilidade pela via do enfrentamento dos conflitos e da construção coletiva de um pacto societário em torno do avanço da justiça ambiental.

Nesse sentido, a EA assume papel importante na compreensão dos fatores e contradições que sustentam conflitos e diferentes projetos de sustentabilidade. Tratar os conflitos ambientais em um processo educativo pode colocar em evidência a omissão com os grupos sociais em condições de vulnerabilidade e contribuir para a articulação de lutas em defesas de seus territórios (JABER e SATO, 2010).

Nesse processo de politização da educação, um segundo deslocamento é favorecido: o reconhecimento de atores sociais que sofrem práticas de exclusão e injustiças ambientais, contrariamente à abordagens que ao privilegiarem identificar, analisar e buscar soluções para problemas ambientais o fazem sob uma ótica conservacionista ou pragmática, ocultando os sujeitos sociais que sofrem injustiças ambientais e/ou lutam por sua superação (LAYRARGUES; LIMA, 2011).

O conflito ambiental recupera a centralidade dos atores sociais em disputa. Segundo LOUREIRO (2003) em uma perspectiva de educação ambiental transformadora, o sentido de partir dos grupos sociais em situação de maior vulnerabilidade ambiental é destacar a realidade da maioria, é democratizar o acesso à informação, é entender a sociedade em suas múltiplas contradições.

Esse segundo deslocamento se manifesta quando Guanabara, Gama, Eigenheer, (2008, p. 129) descrevem diferenças no tratamento pedagógico da temática resíduos sólidos a partir de diferentes perspectivas: a Pedagogia dos 3 R's, o Consumo Ético e Responsável e a Teoria do Risco e Injustiça Ambiental. Os autores admitem que, embora os problemas relacionados com poluição e resíduos possam ser considerados problemas globais, diferentes classes sociais não estão expostas aos mesmos tipos, nem ao mesmo grau, aos riscos ambientais gerados a partir desses problemas. Assim, defendem que projetos de educação ambiental "deveriam incorporar os conceitos de risco e de injustiça ambiental ao seu discurso, ainda mais em comunidades carentes onde o risco é maior e o acesso à informação é menor"

A defesa de uma educação política, ética e moral no âmbito de processos educativos que se pretendam emancipatórios, em contraposição á uma prática educativa desvinculada de compromisso social parece ser um ponto comum entre os artigos pesquisados. Fazer educação com compromisso social segundo Layrargues (2009) 
significa reestruturar a compreensão da educação ambiental, para estabelecer a conexão entre justiça ambiental, desigualdade e transformação social.

O desenvolvimento da responsabilidade social e de uma formação orientada por princípios éticos envolve uma intrincada combinação de conhecimentos, capacidades, interesses e atitudes. Esse desenvolvimento para Kaza (2002) depende, dentre outros elementos, de experiências curriculares, nomeadamente da observação, vivência e análise coletiva de situações de conflito e injustiça ambiental. Essa autora analisa a aprendizagem ocorrida ao longo de um curso de justiça ambiental, em que estudantes foram convidados a um tour com paradas em regiões potencialmente tóxicas. A aprendizagem dos alunos e alunas, segundo a autora, envolveu superar negações sobre a existência de processos de injustiças ambientais locais, lidar com as próprias impressões ambivalentes sobre os movimentos de libertação, reconhecer crenças, experiências e valores para compreender as relações de poder presentes nas injustiças e conflitos ambientais.

\section{Considerações finais}

A julgar pelos periódicos pesquisados, a interface da educação ambiental com conflitos ambientais e justiça ambiental ainda é incipiente. Uma explicação para isso, talvez esteja na semelhante incipiência do debate sobre a relação entre desigualdade social e exposição de populações marginais aos problemas ambientais no amplo e diverso campo ambiental. Podemos verificar sua frágil expressão tanto pela baixa quantidade de publicações nessa linha, quanto pela baixa frequiência de relatos de pesquisa empírica.

No entanto, ainda que de forma incipiente, percebemos que referências à justiça e conflito ambientais no âmbito da EA vêm sendo mobilizadas no sentido de rever concepções e práticas tradicionais de EA, postas a serviço da alienação e desigualdade socioambiental.

Compreender melhor a articulação entre esses dois campos de conhecimento pode apontar caminhos para o desafio de fortalecer processos educativos que buscam contextualizar, politizar o debate ambiental e problematizar as contradições dos modelos de desenvolvimento e de sociedade experimentadas local e globalmente.

\section{REFERÊNCIAS}

ACSELRAD, H.; MELLO, C.C. A.; BEZERRA, G. N. O que é Justiça Ambiental.

Rio de Janeiro: Garamond, 2009. 
ACSERALD, H. As práticas espaciais e o campo dos conflitos ambientais. In: Conflitos ambientais no Brasil. Rio de Janeiro: Relume Dumará, 2004.

ALIER, J. M. O Ecologismo dos Pobres. São Paulo: Contexto, 2007.

BRYMAN, A. Social Research Methods. Oxford University Press, USA; 2 edition, p. 2004.

CARVALHO, I. C. M. Educação para sociedades sustentáveis e socialmente justas. Revista Eletrônica do Mestrado em Educação Ambiental. v. especial, pag. 46 a 55, dez., 2008.

FILHO, C. B. Direito, Justiça e Meio ambiente: fundamentos para uma educação ambiental dos bacharéis. Revista Eletrônica do Mestrado em Educação Ambiental, v. 27, p. 44-56, julho a dezembro de 2011.

FIOCRUZ, FASE, Mapa da Injustiça Ambiental e Saúde no Brasil. Disponível em http://www.conflitoambiental.icict.fiocruz.br/index.php. Acesso em: 25 de agosto de 2010.

GUANABARA, R.; GAMA, T.; EIGENHEER, E. M. Os resíduos Sólidos como Tema Gerador: da pedagogia dos 3R's ao Risco Ambiental. Revista Eletrônica do Mestrado em Educação. Ambiental. V. 21, p. 121 - 132, julho a dezembro de 2008.

JABER, S.; SATO, M. Polissemia dos Conflitos Ambientais do Estado do Mato Grosso - Brasil. Revista Eletrônica do Mestrado em Educação. Ambiental, v. 24, p. 443459, janeiro a julho de 2010.

KAZA, S. Teaching Ethics through Environmental Justice. Canadian Journal of Environmental Education, Vol 7(1), p. 99 a 109, Spring 2002.

LAYRARGUES, P. P.; LIMA, G. Mapeando as Macro-tendências politico-pedagógicas da Educação Ambiental no Brasil. In: Anais do VI Encontro Pesquisa em Educação Ambiental. USP: Ribeirão Preto, 2011.

LAYRARGUES, P. P. Educação ambiental com compromisso social: o desafio da superação das desigualdades. In: LOUREIRO, C. F. B; LAYRARGUES, P. P.; CASTRO, R. S.(orgs.). Repensar a educação ambiental: um olhar crítico. São Paulo: Cortez, 2009. P. 11-31.

LOUREIRO, C. F. B.; BARBOSA, G. L.; ZBOROWSKI, M. B. Os vários "ecologismos dos pobres" e as relações de dominação no campo ambiental. In: LOUREIRO, C. F. B; LAYRARGUES, P. P.; CASTRO, R. S.(orgs.). Repensar a educação ambiental: um olhar crítico. São Paulo: Cortez, 2009, p. 81-118. LOUREIRO, C. F. B. Premissas Teóricas para uma Educação Ambiental Transformadora. Ambiente e Educação, Rio Grande, Vol 8, p. 37-54, 2003. 